\title{
A standardized description of European Sminthuridae (Collembola, Symphypleona), 1: genera Lipothrix, Gisinurus, and Caprainea
}

\author{
Pierre Nayrolles \\ Laboratoire de Zoologie, Ecobiologie des Arthropodes édaphiques, UPR CNRS 90 14, Université Paul \\ Sabatier, 118 route de Narbonne, F-31062 Toulouse Cédex, France
}

Keywords: Collembola, Symphypleona, Lipothrix, Gisinurus, Caprainea, chaetotaxy, taxonomy

\begin{abstract}
A new standard description of Collembola Symphypleona is proposed. In particular, a standard table of the appendicular chaetotaxy (antennae, legs, and furcula) is given. According to this presentation, the following species are redescribed: Lipothrix lubbocki (Tullberg, 1872), Gisinurus malatestai Dallai, 1970, Caprainea marginata (Schött, 1893), and Caprainea bremondi (Delamare \& Bassot, 1957).
\end{abstract}

\section{Résumé}

Nous exposons un nouveau standard de description pour les Collemboles Symphypléones. Nous proposons notamment un tableau type de la chétotaxie des appendices (antennes, pattes et furca). A l'aide de cette présentation standard, nous redécrivons les espèces suivantes: Lipothrix lubbocki (Tullberg, 1872), Gisinurus malatestai Dallai, 1970, Caprainea marginata (Schött, 1893), et Caprainea bremondi (Delamare \& Bassot, 1957).

\section{Introduction}

The aim of this work is not only to redescribe some species of Symphypleona, but also to standardize the presentation of their taxonomic characters, most of which are based on chaetotaxy. The head and body chaetotaxy, which is difficult to observe and standardize, is being studied by J.M. Betsch and the trichobothrial pattern is now well known through the works of Richards (1968), Betsch (1980), and Betsch \& Waller (1989). The study of the appendicular chaetotaxy is easier and we have been able to establish the setal patterns of appendages (Nayrolles, 1988, 1990a, 1990b, 1991).

During the present work, we have given a great deal of attention to the ontogeny of chaetotaxy, and our studies were based upon a wide taxonomic range. This approach is different from Bretfeld's one (1990), since he studied four species belonging to only one family. Such a study, based on a too small taxonomic range, does not allow to build up a chaetotaxic system which would be applicable to all Symphypleona. We could make other criticisms (e.g. the problem of setae counting), but review of Bretfeld's work is beyond the scope of the present paper.

The nomenclature of setae is given in our previous papers. Until now, chaetotaxic tables required two and a half pages. So, a size reduction is necessary. We propose to change the legend on the left side of the tables by a set of symbols.

At generic and specific level, only few taxonomic works on Symphypleona are available, viz. those by Stach (1956) and, limited to Europe, by Gisin (1960). Some studies improving the knowledge of genera characteristics have been made by Richards (1968) and Betsch (1980).

In this work we will study species of the genera Lipothrix, Gisinurus, and Caprainea. These genera will be defined with emphasis on apomorphic characters.

We use symbols for designating setae. It would be needless and too long to list all setal symbols. Indeed, these symbols are built up by using a logic sys- 
tem, so the explanation of this system is sufficient. In the first part of this paper we deal with the nomenclature of setae. Concerning some setae which do not pertain to our system of nomenclature, the symbols we give to them can be regarded as abbreviations. These symbols are listed below.

The following abbreviations are used:

\begin{tabular}{|c|c|}
\hline ad. & $=$ adult \\
\hline n. app. & $=$ anal appendage \\
\hline & $=$ antennal segment \\
\hline ph. diag. & $=$ cephalic diagonal \\
\hline up & $=$ cup-like organ \\
\hline u & $=$ mucronal seta \\
\hline & $=$ occurrence \\
\hline v. org. & $=$ oval organ \\
\hline rc & $=$ subcoxal process (only used in tables) \\
\hline & $=$ instar \\
\hline 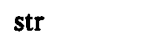 & $=$ chaetotaxic structure (only used in tables) \\
\hline Ke & $\begin{array}{l}=\text { external (dorsal) microchaeta of antennal III } \\
\text { organ }\end{array}$ \\
\hline & $\begin{array}{l}=\text { internal (ventral) microchaeta of antennal III } \\
\text { organ }\end{array}$ \\
\hline
\end{tabular}

Nomenclature and vocabulary used for describing chaetotaxy

\section{Principles of chaetotaxic nomenclature}

We recall the general principles of setal arrangements on appendices and the nomenclature which is based on Nayrolles (1988, 1990a, 1990b, 1991). In our previous papers we used words for describing the chaetotaxy; several words were neologisms. We will translate them and quote French words between brackets.

First, we distinguish " $G$ setae" from "H setae". $\mathrm{G}$ setae belong to generatrices and $\mathrm{H}$ setae to intergeneratrices. We call a "generatrix" [génératrice] a row of setae along an appendix. Fundamentally, there are 8 generatrices, viz.: Ge (external), Gae (anterior-external), Ga (anterior), Gai (anteriorinternal), Gi (internal), Gpi (posterior-internal), Gp (posterior), and Gpe (posterior-external). An "intergeneratrix" [intergénératrice] is a setal row between two generatrices. We can observe intergeneratrices only on ant. IV. The intergeneratrix between $\mathrm{Ge}$ and $\mathrm{Gae}$ is written Heae, the one between Gae and $\mathrm{Ga}$ is written Haea, etc. Thus, the appendicular chaetotaxy shows a setal organization in generatrices and intergeneratrices, and so we can say that the chaetotaxy has a longitudinal structure.

Second, as well as the longitudinal structure, a transversal structure can sometimes be observed. Whorls of setae make up this transversal structure. We name "whorlation" [verticillation] the different organizations of setae in this transversal structure; indeed we can observe several degrees of structure (easiness to recognize whorls). An appendicular segment on which we cannot recognize any whorl is described as "unwhorled" [averticillé]. Conversely, an appendicular segment bearing obvious whorls is "euwhorled" [euverticillé]. If whorls are at a right angle to the axis of the appendicular segment, we say that the euwhorlation is right [euverticillation droite], or we say that the euwhorlation is sloping [euverticillation inclinée]. Moreover, setae can be present between two whorls on tibiotarsi and furcula; these setae make up an "interwhorl" [interverticille]. From apex to basis, interwhorls are numbered with Arab numerals, and whorls with Roman numerals (except one part of ant. IV, where the whorls are generally numerous; for practical reasons we use Arab numerals here).

Third, the chaetotaxic nomenclature combines the number of whorls or interwhorls with the letters of generatrices or intergeneratrices. For instance, Iae is the seta on whorl I and on generatrix Gae. In addition, letters like A (for apical) or B (for basal) are added when the segment is divided in several parts. For instance, on ant. IV the seta AIIe is situated on the apical part (A), within the second whorl of this part (II), and on the external generatrix (e).

Fourth, suppose that one wants to refer to a seta, if the context does not say which segment bears this seta, it is necessary to indicate it. Two letters are used for symbolizing segments; for instance: AQ for ant. IV, TI for tibiotarsi, DE for the dens, etc. (see below). Within a setal symbol, the segment letters are written between parentheses, e.g.: (AQ)AIIe. As far as the legs are concerned, the numbers 1,2 , and 3 refer to the pair in question. For example, TI1 is used for the foretibiotarsus, and then (TI1)IIa is the seta on the foretibiotarsus, on the second whorl, and on $\mathrm{Ga}$. When we consider two homeotypic setae together, like the couple 
(TI1)IIa and (TI2)IIa, we write the numbers of both legs separated by a comma, e.g.: (TI1,2)IIa. When we consider all tibiotarsi, we write: (TI.)IIa. The point means "all legs" (this is shorter than to write $1,2,3)$.

We give the symbols for appendicular segments in the following list:

$\begin{array}{ll}\text { Antenna AP } & =\text { first antennal segment } \\ \text { AD } & =\text { second antennal segment } \\ \text { AT } & =\text { third antennal segment } \\ \text { AQ } & =\text { fourth antennal segment } \\ \text { Legs } & =\text { basal subcoxa } \\ \text { SA } & =\text { apical subcoxa } \\ \text { CX } & =\text { coxa } \\ \text { TR } & =\text { trochanter } \\ \text { FE } & =\text { femur } \\ \text { TI } & =\text { tibiotarsus } \\ \text { PT } & =\text { pretarsus } \\ \text { MA } & =\text { manubrium } \\ \text { DE } & =\text { dens } \\ \text { MU } & =\text { mucron }\end{array}$

The nomenclature of appendicular setae

Now we can accurately expose the chaetotaxic nomenclature of every appendix.

Antenna. - Ant. I bears 7 setae which are written e, ae, a, etc., each of them belonging to one generatrix.

The primary setae on ant. II and ant. III can be divided into an apical set (setae Ae, Aae, etc.) and a basal set (setae Be, Bae, etc.). Both setae of the antennal III organ do not belong to a generatrix; they are written $\mathrm{Xe}$ (the external one) and $\mathrm{Xi}$ (the internal one). Considering the secondary setae, on each generatrix, we add to the generatrix letter(s) the following symbols: " -1 ", “ 0 ", " +1 ", " +2 ", and " +3 ". The setae 0 (e.g. a0) appear generally at the 2 nd instar. On each generatrix, by comparison with the place of the seta 0 , we can observe the seta -1 to the apex, and successively towards the basis the setae $+1,+2$, and +3 . For instance, on ant. III of Caprainea bremondi, Gpe bears the following setae: pe 0 at the 2 nd instar, pe -1 and pe +1 at the $3 \mathrm{rd}$ instar, and finally pe +2 and pe +3 at the 4 th instar.

We can divide ant. IV into three sections: A (api- cal), M (median), and B (basal). Generally, we can also divide $B$ in three parts, which are from apex towards basis: BA, BM, and BB. The section A bears three whorls (AI, AII, and AIII) and at its tip one seta written AA (no definite generatrix for AA). The section $B$ has a variable number of whorls. From apex to basis, these whorls are written: M1, M2, M3 ... Concerning the section B, BA is a whorl, BB is a whorl as well, but very incomplete, and BM has a special chaetotaxy. Indeed, the setae of BM are not idionymic (Grandjean, 1949). So, one cannot give any of these setae a name. Except AA and the setae of BM, we name the setae of ant. IV with reference to whorls and generatrices or intergeneratrices, e.g.: AIIpe, M3ae, BAp, BBe ...

Legs. - As far as the segments of legs, from femur to subcoxae, are concerned, we cannot observe whorls. For one segment (viz. femur), on each generatrix, setae are numbered from apex to basis, and the number follows the generatrix letter(s); for instance: ai1, ai2, ai3 ... Moreover, we can observe oval organs on these segments. The letter $O$ is used for referring to such organs. For example: Oil and $\mathrm{Oi} 2$ on trochanter; both belong to $\mathrm{Gi}$, and $\mathrm{Oil}$ is the most apical.

Whorls and interwhorls are present on tibiotarsi. The fourth interwhorl has two setae on Gai, and two setae on Gpi. So, we consider that two layers make up the fourth interwhorl. We number 1 the apical layer, and 2 the basal one. Concerning the other generatrices, we consider that their setae belong to the first layer (because of setal places). The setae 4ai 2 and 4 pi 2 belong to the second layer, the other setae (4ael, 4a1, 4ail, etc.) to the first layer.

The letter $O$ is used for an ov. org. (e.g. Olpe). Sometimes two additional setae are present at the apex of the tibiotarsi; they are named "setae K". The basal part of tibiotarsi is named $F$. The primary setae of this part are designated by FP; they are: FPe, FPae, and FPpe. The secondary setae are designated by FS (e.g. FSa). If a seta FS belongs to the same generatrix as a seta FP, the seta FS can be either apical or basal to the seta FP. If FS is apical we add the symbol $\uparrow$ (seta FSe $\uparrow$ ), else we add ! (seta FSpel).

Furca. - The manubrium is devoid of whorls, so 
we number setae on each generatrix, from apex to basis, in this way: p1, p2, p3.

On the dens, we distinguish one basal whorl (B) from whorls and interwhorls on the median and apical part. The setae belonging to $\mathrm{B}$ are written $\mathrm{Be}$, Bpe, etc. The other setae are written IIp, IIIp, etc., when they belong to whorls, and $3 p, 4 p$, etc., when they are on interwhorls.

\section{Morphology of setae}

We recall some of the special shapes that setae sometimes have, and we translate French words that we used to describe setal morphology (Nayrolles, 1991).

According to the size criterion, we distinguish microchaetae, mesochaetae, and macrochaetae. Besides, we consider that differences, on the one hand between microchaetae and mesochaetae, and on the other hand between macrochaetae and mesochaetae, have to be well marked. So, only really short setae will be regarded as microchaetae, and only really long setae as macrochaetae.

We recall that an ov. org. is a very short microchaeta with a special shape. We coined the word "acanthoïde" (acanthoid) for a spine-like seta. The term "microacanthoïde" (microacanthoid) has been used for designating a spine-like microchaeta.

The mesochaeta sensu stricto corresponds to the ordinary pointed seta. In our descriptions the word mesochaeta will be used in its restricted sense. Among the types of mesochaetae (in broad sense), we can differentiate between blunt and pointed mesochaetae.

We coined the following expressions: "soie cucumiforme" (cucumiform seta) for a mediumsized blunt mesochaeta, "soie bacilliforme" (bacilliform seta) for a short blunt mesochaeta, "soie gladiforme" (gladiform seta) for a rather short and thick seta looking like a two-edged sword, and "soie en crosse" (crooked seta) for a blunt seta ending by a crook.

\section{The problem of chaetotaxic variability}

For every species, whenever possible, only one population was used for studying the chaetotaxy. Sometimes comparisons with specimens from other populations were made. It seems that chaetotaxic variation between populations is scanty.

For a variable seta on an appendix, let $P$ be the modality "presence of the seta" and A the modality "absence of the seta". The great proportion of asymmetric specimens that we have met in our observations can be explained by considering that the frequencies of the different types of specimens (namely PP, PA and AA) approximate a binomial law. Consequently, as far as the presence/absence of variable setae is concerned, both sides of one specimen can be considered as approximately independent. This model of variability has been recorded previously in Acari by Grandjean (1939, 1949, 1952).

For every species we have studied one (sometimes two) 1st instar specimen, two 2nd instar specimens and four specimens of every later instar. At this step, we have determined, for every instar of every species, the absent, present, or variable setae. In most cases, the variable setae appear either at the 3rd instar, or at the 4th instar. In order to define their frequencies with better precision, other preparations were also made. During these new observations, only the setae defined as susceptible of variation were studied. When the material was sufficient, we made about six complementary preparations for each instar, so as to study about ten specimens. As appendages are paired, this results in about twenty observations. Thanks to the replicated observations, for each instar, we can definitively define the setae that we consider as present, absent, or variable.

According to Nayrolles $(1989,1991)$, we consider a seta as being variable when it is present in one fifth to four fifths of the observations (below one fifth the seta is considered as absent, and above four fifths the seta is considered as present and constant). The aim is to limit the number of variable setae given in each species description; this makes the data processing easier during an ontophylogenetic analysis. The rate of presence of an 
idionymic seta considered as variable is estimated by its occurrence (oc). The occurrence is equal to the probability of presence given by one digit.

In the case of a set of setae for which we calculate the variable "total number of setae", we give the values corresponding to the interval which includes at least $80 \%$ of the observations (this kind of descriptor is noted $n 80 \%$ ).

\section{The standardized presentation of descriptions}

First, we present a standard table of chaetotaxy (cf. Tables I-IV).

The symbols of the different segments are written in the left column. In the second column, for several cases, two Greek letters are used: $\Delta$ for secondary setae present, or setae with a particular form, or any remark, and $\Pi$ for absent primordial setae. We recall the definition of the primordial chaetotaxy (Nayrolles, 1990a, 1990b, 1991). Let us consider an appendicular segment and all primary setae that we can find by studying several species within a zoological group; then, let us build up, on the one hand, the set of primary setae which are present in all species, and on the other hand, the set of primary setae which are absent in one or several species. If the number of setae of the second set is actually smaller than the number of setae of the first set, we can define a primordial chaetotaxy which corresponds to the union of both sets (thus, all possible primary setae). Defining a primordial chaetotaxy on an appendicular segment is a good way to shorten descriptions, because only absent setae are given.

The upper part of the table concerns the antennae with symbols as follows (Nayrolles, 1991): AP = ant. $\mathrm{I}, \mathrm{AD}=$ ant. II, $\mathrm{AT}=$ ant. III, $\mathrm{AQ}=$ ant. IV. Concerning AQ, "str" is used for the chaetotaxic structure, A, M and B for the different sections of this segment. The $\mathrm{H}$ setae are distinguished from the $\mathrm{G}$ setae. The middle part of the table concerns the legs and is vertically divided in three parts. From left to right, these three parts correspond to the anterior, median, and posterior legs, respectively. We recall the symbols of the segments (Nayrolles, 1990a): $\mathrm{SB}=$ basal subcoxa, $\mathrm{SA}=$ apical subcoxa, $\mathrm{CX}=$ coxa, $\mathrm{TR}=$ trochanter, $\mathrm{FE}=$ femur, $\mathrm{TI}=$ tibiotarsus. In the second column, prc
$=$ subcoxal process, $\mathbf{K}=$ presence (noted + )/absence (noted - ) of $\mathrm{K}$ setae, FP = presence/ absence of FP setae. As far as the tibiotarsi are concerned, we consider that the primary setae on the whorls constitute the primordial chaetotaxy. The lower part of the table concerns the furcula. The symbols used (Nayrolles, 1990b) are: MA = manubrium, $\mathrm{DE}=$ dens, $\mathrm{MU}=$ mucro.

Within the three parts of the table, the instar of appearance of a seta is given by a letter: $P$ for a primary seta, $D, T, Q$, and $C$ for a seta emerging at the 2nd, 3rd, 4th, or 5th instar, respectively (symbols from Nayrolles, 1991). For example, on ant. II the seta $\mathrm{i} 0$ appears at the 2 nd instar, and so in tables we write: "D: i0". When a seta is variable at the instar in which it appears, the letter that symbolizes this instar is written between parentheses; if in a later instar it becomes constant, this instar is given as well. For example, $(\mathrm{T})$ means that a seta appears with variability at the 3 rd instar and remains variable; (T)Q means that a seta appears with variability at the 3rd instar and becomes constant at the 4th.

The following categories in already published tables are not used here:

- for AT: "Papille tégumentaire" = "integumentary protuberance”, cf. Richards (1968);

- for DE: "Papilles dentales" = "dental papillae", cf. Richards;

- for FE: "cup" = "organe en cupule" which we can translate into cup-like organ.

The integumentary protuberance of ant. III and the dental papillae are lacking in Sminthuridae. The cup-like organ, which is very slender, is very difficult to observe. Nevertheless, good optical material allowed us to investigate this organ. Its presence will be quoted in the text.

Concerning ant. IV, when the section $M$ has not many whorls (Lipothrix lubbocki), the occurrences of $\mathrm{H}$ setae are given by the following mean: for example, concerning Heae of $L$. lubbocki, 1-1-1-1-0/0 signifies that, from the apex to the basis, each of the first four whorls of M (M1, M2, M3, M4) bears one seta $(o c=1)$, the last (M5) does not $(o c=0)$ and the section B (separated by a diagonal) does neither. When $\mathrm{M}$ has many whorls, we do not display the occurrence of each seta, but we merely say whether each intergeneratrix reaches BA or BM. Besides, we give the mean $(m)$, the maximum 
(max) and the minimum (min) of the following antennal variables: Heae*, Hppe*, and $h^{*}$. Heae* is the number of setae on Heae which are present on $\mathbf{M}$ and B; Hppe* is the number of setae on Hppe which are present on $M$ and $B$; and $h^{*}=$ $\left(\right.$ Heae $^{*}+$ Hppe $\left.^{*}\right) / 2$.

For each species we give a chaetotaxic table and a text. Concerning the text of the antennae, some explanations are necessary. We give the means of the antennal ratios ant. I : II : III : IV and ant. : ceph. diag. Then we give the mean $(m)$, the standard deviation $(s)$, the minimum (min) and the maximum (max) of three chaetotaxic variables (noted $G, I S h^{*}$ and $R S h$ ) which are characteristic of ant. IV. $G$ is equal to the number of $G$ setae on ant. IV. $I S h^{*}=h^{*} /(V+1)$, wherein $h^{*}$ (vide supra) is equal to the half of the number of setae on Heae and $H$ ppe present on the sections $M$ and $B$, and $V$ is equal to the number of whorls on M. RSh is equal to four times the total number of setae on Heae and Hppe divided by $G$.

\section{Lipothrix Börner, 1906}

The ontogenetic loss of the trichobothrium D and the pair of mesothoracic finger-like papillae are noteworthy characters (within the family Sminthuridae, Neosminthurus shows these characters as well). Three species belong to the genus Lipothrix: L. lubbocki (Tullberg, 1872), L. italica (Cassagnau, 1968), and $L$. bernardi (Delamare, 1953). We have studied L. lubbocki.

\section{Lipothrix lubbocki (Tullberg, 1872)}

(Figs. 1-6, Table I)

Material examined. - Material collected by A. Bedos. France, dep. Aude, wood of Pinet (south of Belesta forest), alt. $880 \mathrm{~m}$; dead leaves and branches at the edge of the forest on peaty soil, fauna extraction with Berlese; 19-V-1983 and 2-VI-1983; about 60 juvs. and 20 adults mounted.

Dep. Pyrénées-Orientales; forest of Laroque-des-Albères; humus, fauna extraction with Berlese; 25-IX-1986; 4 adults mounted (Bedos leg.).

Description. - Number of juv. st. $=4$.

Size ad. male: $0.7 \mathrm{~mm}$; female: $0.7-0.9 \mathrm{~mm}$.
Color. Background very dark blue, usually uniform, sometimes lighter (yellow-orange tint) on the dorsal area. Appendages with pigment. Eyepatches black.

Great abd. Trichobothria: A short, appears at 2nd st., B short, appears at 3rd st., C long, appears at 2 nd st.; A, B, C in very open inverted pattern. From 1st st., one pair of mesothoracic vesicles. One pair of neosminthuroid setae which are microacanthoids at 1st st. Two kinds of dorsal setae (Figs. 5-6). Some setae are rough, with apex truncate and really thick, others are less rough and less thick. Dorsal area covered with large secondary grains.

Antennae. Antennal ratios: nearly the same for both sexes, ant. I : II : III : IV = $1: 1.7: 2.2: 3.3$ and ant.: ceph. diag. $=1.2$. In this species, the chaetotaxic variables are constant; their values are: 78 for $G, 0.75$ for $I S h^{*}$, and 0.56 for $R S h$. First three antennal segments with gladiform setae and ov. org. Ant. IV relatively short, with slight subsegmentation.

Head. Eyes: $8+8$; one of the two setae on the eyepatches changed into an ov. org. (Fig. 4). Interocular and frontal zones with thick setae. Labral formula: 6/5-5-4. Major part of head covered with large secondary grains.

Legs (Figs. 1-3). Femur: cup present. (FE3)pl being a winged acanthoid on wide basis ending in a filament. Several acanthoids on hindlegs. (TI.)Ie curved and shifted to posterior side. On tibiotarsi, setae on inner side are sharper and thicker than those on outer side (very distinctly for IIIi and IVi). Setae on outer side, at the basis of whorl II, are blunt. This morphology can also be found on different setae of more proximal segments. Probably, the weakly clavate shape of some setae corresponds to the increase of the blunt character. Claws of all legs with pseudonychia and large tunica. Inner crest of claw with strong tooth on forelegs and mesolegs, and with small tooth on hindlegs. Empodial appendage of every leg without tooth on its outer lamella. Empodial filament long and rather thick.

Ventral tube. From 2nd st., sacs warty. Chaetotaxy: apical flaps with one pair of primary setae, corpus without seta.

Retinaculum. At 1st st. rami tridentate, bidentate from 2nd. Chaetotaxy: on anterior lobe one pair of 
Table I. Appendicular chaetotaxy of Lipothrix lubbocki.

\begin{tabular}{|c|c|c|c|c|c|c|c|c|c|c|c|}
\hline \multirow{3}{*}{ AP } & & \multicolumn{10}{|c|}{ ai is an ov. org. $p$ is a microacanthoid, the other setae are gladiform. } \\
\hline & $\frac{\Delta}{\Pi}$ & \multicolumn{10}{|c|}{ Bpe } \\
\hline & $\Delta$ & \multirow{2}{*}{\multicolumn{10}{|c|}{$\begin{array}{l}\text { D: io } T: \theta+1, i+1 \quad Q: a+1, i+2 \\
\text { Ap is an ov. org., and except io, } i+1 \text { and } i+2 \text {, the other setae are gladiform. }\end{array}$}} \\
\hline & & & & & & & & & & & \\
\hline \multirow[t]{5}{*}{$\overline{A T}$} & $\Pi$ & \multicolumn{10}{|c|}{-} \\
\hline & \multirow[t]{4}{*}{$\Delta$} & & & $\mathrm{G}_{\theta}$ & Gao & $\mathbf{G a}$ & Gai & Gi & Gpi & \begin{tabular}{|l|l|}
$G p$ & $G p \theta$ \\
\end{tabular} & Other setae: - \\
\hline & & & Setae -1 & & & $\mathbf{Q}$ & & $\mathbf{Q}$ & $\mathbf{a}$ & $T$ & \multirow{3}{*}{$\begin{array}{l}\text { Ap and } \mathrm{Bp} \text { are ov. org. Ape is a blunt microchaeta. } \\
\mathrm{A \theta}, \mathrm{Aa}, \mathrm{Be}, \mathrm{Ba \theta}, \mathrm{Ba}, \mathrm{Bai}, \mathrm{Bi}, \mathrm{aeO}, \mathrm{a}-1, \mathrm{a}+1, \mathrm{pe-1}, \mathrm{pe0} \text { are } \\
\text { gladiform. }\end{array}$} \\
\hline & & & Sotae 0 & & D & & D & D & D & D & \\
\hline & & & Setae +1 & & & $\mathbf{Q}$ & & & & & \\
\hline \multirow[t]{6}{*}{$\overline{A Q}$} & str & \multicolumn{10}{|c|}{$\begin{array}{l}\text { B completely zoned with a definite chaetotaxy. Section } M \text { euwhorled. Right euwhorlation. Basal inner inclination of Gae, } \\
\text { Ga and Gp. Apical folding of Ga with Alla shifted towards inner side. } \\
\text { Subsegmentation formula: } 1+3+1=(A+M 1,2)+(M 3,5)+(B) \text {. Subsegmentation right and hardly distinguishable. }\end{array}$} \\
\hline & \multirow[t]{3}{*}{$\bar{A}$} & $\Pi$ & \multicolumn{9}{|c|}{ Allpi } \\
\hline & & $\mathrm{H}$ & \multicolumn{9}{|c|}{ Alleae, Allppe } \\
\hline & & $\Delta$ & \multicolumn{9}{|c|}{$\begin{array}{l}\text { Apical bulb: - Subapical organ: rather large, strongly clavate } \\
\text { Allpe is a crooked seta }\end{array}$} \\
\hline & \multirow{2}{*}{$\begin{array}{l}\text { M } \\
\mathbf{R} \\
\mathbf{B}\end{array}$} & $\mathrm{H}$ & \multicolumn{9}{|c|}{ The occurrences of $H$ setae on M \& $B$ are: for Heae 1-1-1-1-0/0 and for Hppe 1-1-1-1-1/0. $m(h)=4.5$. } \\
\hline & & $\mathbf{G}$ & \multicolumn{9}{|c|}{ 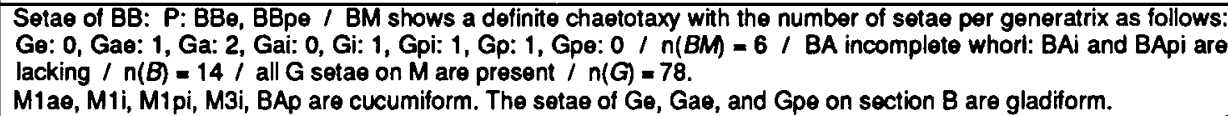 } \\
\hline
\end{tabular}

\begin{tabular}{|c|c|c|c|c|}
\hline \multirow{2}{*}{$S B$} & pre & - & + & + \\
\hline & $\Delta$ & $P: 1$ sota & \multirow{2}{*}{$\begin{array}{l}P: 1 \text { seta } \\
P: 1 \text { seta }\end{array}$} & $T: 1$ ov. org. \\
\hline SA & $\bar{\Delta}$ & $\overline{-}$ & & P:1 seta \\
\hline$\overline{C X}$ & $\bar{\Delta}$ & $\overline{-}$ & P: ae, i1, ms Q: a, Oi1 & $\mathrm{P}: \mathrm{a \theta}, \mathrm{i} 1, \mathrm{~ms}$ \\
\hline \multirow[t]{2}{*}{ TR } & \multirow{2}{*}{$\frac{\Gamma}{\Delta}$} & $\overline{-}$ & T: Oi1, Oi2 Q: ae, a2 & - \\
\hline & & $a 1, i 1$, and $p$ are very weakly clavate & $\begin{array}{l}\text { T: Oi1, Oi2 Q: ae, a2 } \\
\text { p is large, weakly clavate }\end{array}$ & $\begin{array}{l}\mathrm{T}: \text { Oi1, Oi2 Q: ae, a2 } \\
\mathrm{p} \text { is a blunt acanthoid }\end{array}$ \\
\hline \multirow[t]{2}{*}{ FE } & $\Pi$ & $a \mathbf{a}^{3}$ & - & $p e 1$ \\
\hline & $\Delta$ & $\begin{array}{c}\text { Q: pe3, pi2, Op } \\
\text { a4 is a sharp acanthoid }\end{array}$ & $Q: a i 2, p \in 3, O p \quad(Q): a 5(o c=0.8)$ & $\begin{array}{l}\text { T: a5 Q: ai2, pe3, Op } \\
\text { p1 is a special acanthoid }\end{array}$ \\
\hline \multirow[t]{5}{*}{$\mathrm{TI}$} & $\bar{\Pi}$ & - & $V_{p}$ & $V_{p}$ \\
\hline & $\mathrm{K}$ & - & - & $=$ \\
\hline & FP & + & + & \pm \\
\hline & $\Delta$ & $\begin{array}{l}\text { T: O2pe } \\
\text { Q: Vai, Vpi, FSa, 4ai1, 4pi1, O1pe, } \\
\text { O3pe, O4pe } \\
\text { C: FSai, FSpi }\end{array}$ & $\begin{array}{l}\text { T: O2pe } \\
\text { Q: Vai, Vpi, FSa, 4ai1, 4pi1, O1pe, } \\
\text { O3pe, O4pe } \\
\text { C: FSai, FSpi }\end{array}$ & $\begin{array}{l}\text { T: O2pe } \\
\text { Q: Vai, Vpi, FSa, 3a, 3ai, 3i, 4ai1, 4i1, } \\
\text { O1pe, O3pe, O4pe } \\
\text { C: FSai, FSpi, 4pi1 }\end{array}$ \\
\hline & & $\begin{array}{l}\text { le is shifted towards posterior side and } \\
\text { curved towards anterior side. } \\
\text { Vi is a microacanthoid. }\end{array}$ & $\begin{array}{l}\text { le is shifted towards posterior side and } \\
\text { curved towards anterior side. } \\
\text { Vi is a microacanthoid. }\end{array}$ & $\begin{array}{l}\text { le is shifted towards posterior side and } \\
\text { curved towards anterior side. } \\
\text { Ilp, Ilp, Illpi, IVpi are thick and curved } \\
\text { acanthoids. IVp is a small acanthoid. } \\
\text { Vi is a microacanthoid. }\end{array}$ \\
\hline
\end{tabular}

\begin{tabular}{|c|c|c|c|c|c|c|c|c|c|c|c|c|}
\hline \multirow[t]{2}{*}{ MA } & $\Pi$ & \multicolumn{11}{|c|}{ - } \\
\hline & $\Delta$ & \multicolumn{10}{|c|}{$\mathrm{Q}: \mathrm{a} 1, \mathrm{p} \theta 2$} & \multirow{9}{*}{$\begin{array}{l}\text { nicrochaeta } \\
\text { Other setae: } \quad \mathrm{Q}: \mathrm{BBpj} \\
\text { la, lae and Ba are microchaetae. }\end{array}$} \\
\hline \multirow[t]{8}{*}{$\mathrm{DE}$} & $\bar{\Delta}$ & \multirow{7}{*}{$\begin{array}{l}\text { Whorls } \\
\text { I to VI }\end{array}$} & & $\mathrm{G}_{\theta}$ & Gae & $\mathrm{Ga}$ & Gail & $\mathbf{G i}$ & Gpi & Gp & Gpo & \\
\hline & & & $T$ & $P$ & $P$ & $P$ & $\mathrm{P}$ & $\mathbf{P}$ & & $P$ & $P$ & \\
\hline & & & II & & & & & & & 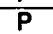 & $P$ & \\
\hline & & & III & & & & & & & $\mathbf{P}$ & $\mathbf{P}$ & \\
\hline & & & IV & & & & & & & $P$ & & \\
\hline & & & $\mathrm{V}$ & & & & & & $\mathbf{Q}$ & $P$ & & \\
\hline & & & $\overline{v l}$ & & & & & & & & & \\
\hline & & \multicolumn{2}{|c|}{ WhorlB } & $\mathbf{Q}$ & & $\mathbf{P}$ & & & $\mathbf{P}$ & $P$ & $\mathbf{P}$ & \\
\hline $\mathrm{MU}$ & $\bar{\Delta}$ & \multicolumn{11}{|c|}{$\begin{array}{l}\text { Chaetotaxy: - Morphology: anterior lamella double, outer lamella smooth, inner lamella serrated; apex } \\
\text { notched. Outer lamella serrated on its basis at 1st st., and becoming smooth during development. }\end{array}$} \\
\hline
\end{tabular}




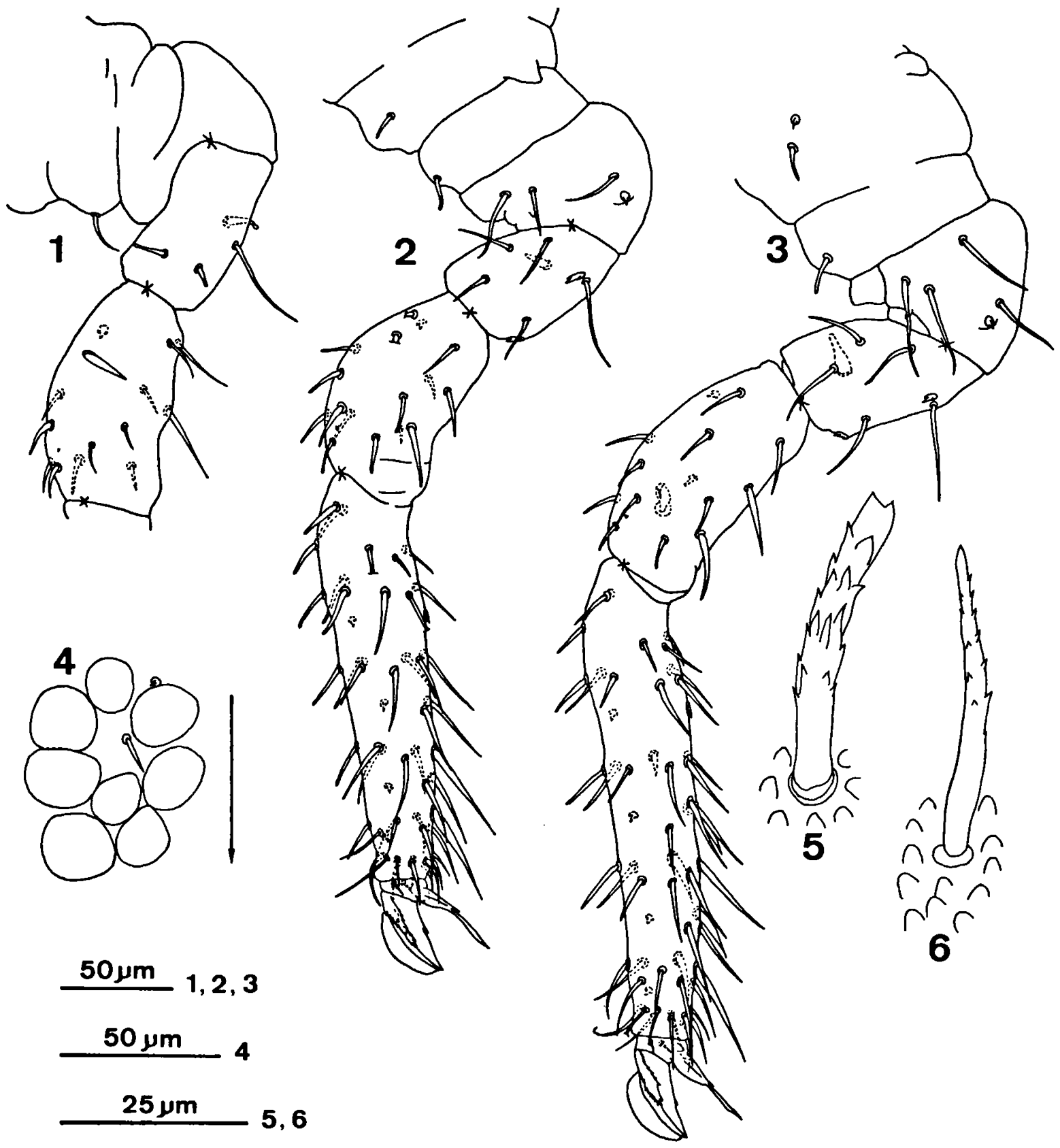

Figs. 1-6. Lipothrix lubbocki ad.: 1, basis of foreleg, anterior view; 2, mesoleg, anterior view; 3, hindleg, anterior view; 4, right eyepatch, arrow indicating bottom of head; 5 , truncate seta on back of great abd.; 6, blunt seta on back of great abd.

setae appears at 3rd st., another pair at 4th.

Furcula. Extensive paurochaetosis. Ia, Iae and $\mathrm{Ba}$ are microchaetae.

Small abd. Made up of abd. V + abd. VI. Trichobothrium: D long, present at 1st st., absent from 2 nd. Female an. app. long, curved and fine- ly serrated. Ratio mucro: an. app. = 1.1. An. app. present in male (being a microchaeta). Genital papilla of male medium-sized with about 24 setae. 


\section{Gisinurus Dallai, 1970}

Gisinurus has only one species: Gisinurus malatestai Dallai, 1970. The following characters of Gisinurus are evolved: absence of (TI.)IIi, size reduction of tibiotarsal ov. org., ontogenetic delay of (DE)IIp, absence of several setae at apex of ant. IV, displacement of (AT)Api during development, claw with socket, only 2 setae instead of 4 on retinaculum in adults. Another noteworthy character (plesiomorphy?) is the absence of increasing heterochaetosis for the primary setae at the basis of ant. III.

\section{Gisinurus malatestai Dallai, 1970}

(Figs. 7-17, Table II)

We did not observe the female, so one part of our description is taken from Dallai (1970b).

\footnotetext{
Material examined. - Spain, prov. Barcelona, between Vallgorguina and Arenys de Munt, alt. $300 \mathrm{~m}$; on a track in undergrowth (Plane-tree, Chestnut-tree, Ilex, maritime Pine) with Gramineae and Agrimonia eupatoria L., Geum urbanum L., Betonica officinalis L., Plantago major L., etc.; collected with a net by Nayrolles (BA15b); 4-IX-1987; only $1 \sigma^{\circ}$ collected and mounted.

The rest of the material was collected by $L$. Deharveng: Spain, prov. Gerona, Montnegre (south-east of Gerona); litter of Corkoak (EGE10); 10-III-1981; 21 juvs. and 3 or or mounted.
}

Description. - Number of juv. st. $=4$.

Size ad. male: $0.7-0.8 \mathrm{~mm}$; female: $0.8-0.9$ mm.

Color. Background is a rather pale shade of purple. Dorsal area of head unpigmented. Eyepatches quite small, black. Antennae purple. Legs and furcula white. Appendages long and slender.

Great abd. Trichobothria: A, B, C appear at 2nd st., in very open inverted pattern. Dorsal setae: long, smooth, thin, and sharp.

Antennae (Figs. 10-17). Antennal ratios: in female (after Dallai), ant. I : II : III : IV = $1: 1.7$ : $3.1: 8.5$ and ant.: ceph. diag. $=2.25$; in male, ant. I : II : III : IV = $1: 1.7: 4.0: 11.3$ and ant.: ceph. diag. $=2.4$. Chaetotaxic variables: for $G: m=$ $120.3 / s=1.58 / \min =117 / \max =123$; for $I S h^{*}: m=0.88 / s=0.025 / \min =0.82 / \max$
$=0.91 ;$ for $R S h: m=0.71 / s=0.019 / \mathrm{min}=$ $0.68 / \mathrm{max}=0.75$. Antennal III organ invaginated. Concerning ant. IV, besides absence of AIIpi (characteristic of the family), AA, AIp and AIpi are lacking. The other characters are: absence of macrochaeta, rather pronounced neochaetosis, and displacement of (AT)Api towards basis during development.

Head. Eyes: $8+8$; eyepatch with 2 setae. Head without macrochaeta. Labral formula: 6/5-5-4.

Legs (Figs. 7-9). Legs long and slender. Femur: cup present. Tibiotarsi with slender ov. org. and thin setae. Note absence of (TI.)IIi and presence of (TI1)FSp from 3rd st. Claw of all legs with a tunica; its inner crest with several small teeth. Lateral crest well developed on hind side, and bearing several teeth; on fore side, the lateral crest hypertrophies into a lamella (pseudonychium) which partly surmounts the claw. Dallai (1970b) compared this lamella with an incomplete tunica. Claw showing socket which opens onto anterior side. Empodial appendage of all legs without tooth on outer lamella. Empodial filament absent.

Ventral tube. From 2nd st., sacs warty. Chaetotaxy: Apical flaps with one pair of primary setae, corpus with a pair from 4th st.

Retinaculum. At lst st. rami tridentate, bidentate from 2nd. Chaetotaxy: on anterior lobe one pair of setae appears at 3rd st.

Furcula. Like other appendages, dentes are long and slender. The most noteworthy characters being the ontogenetic delay of IIp, and Gai with only one seta: Iai.

Small abd. Made up of abd. V + abd. VI. Trichobothrium: D. Genital papilla of male large with about 40 setae. According to Dallai, female an. app. setaceous, without branches, smooth, and gradually tapered.

\section{Caprainea Dallai, 1970}

After he had recognized the validity of the genus Allacma, Dallai (1970a) isolated the species echinatus from the genus Sminthurus by creating the genus Caprainea. Dallai differentiated Caprainea from the Sminthurus-Allacma group on the basis of 


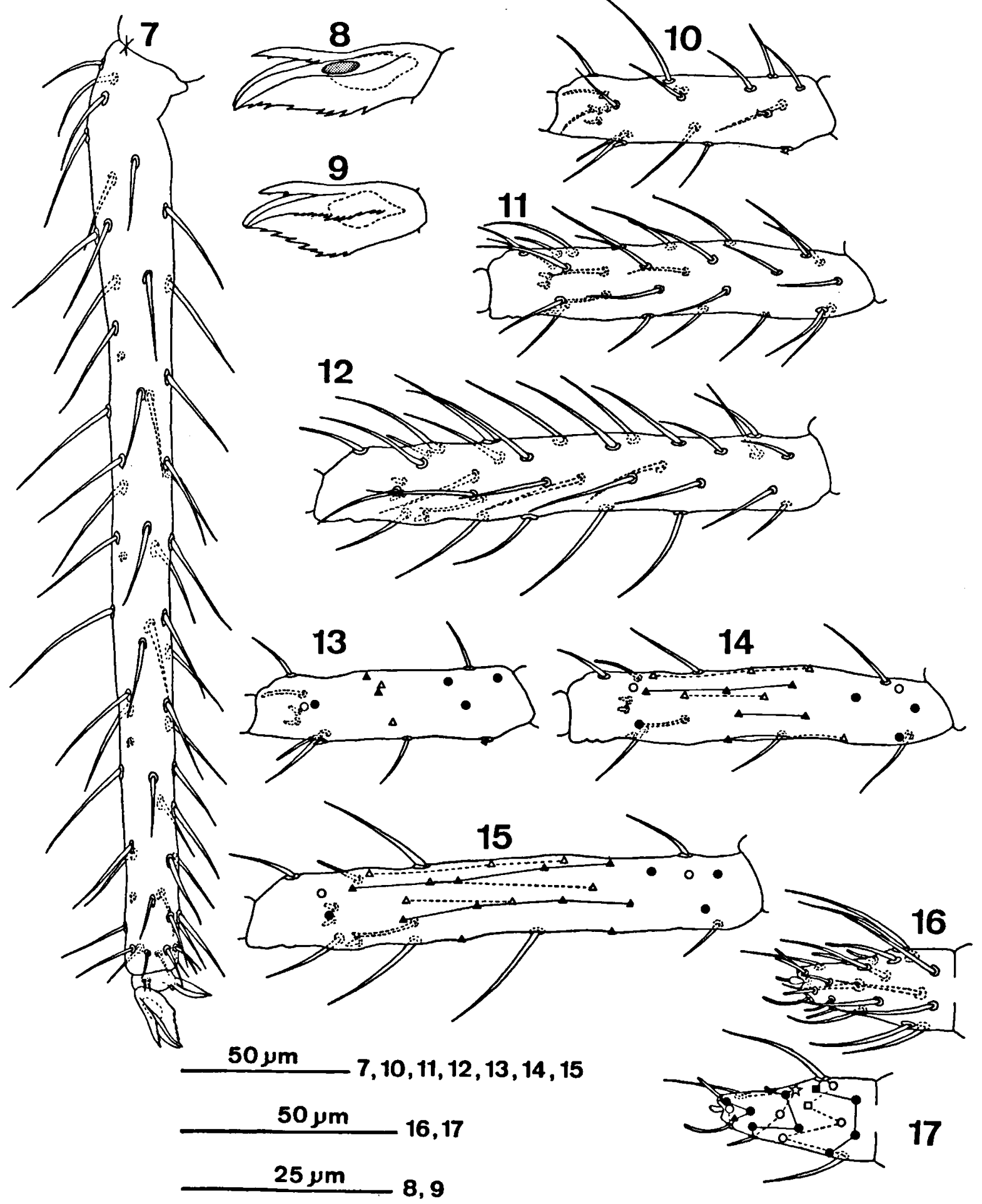

Figs. 7-17. Gisinurus malatestai: 7, ad., mesotibiotarsus, anterior view; 8, detail of claw, anterior view, grey area being orifice of socket which is delimited by dashes; 9 , detail of claw, posterior view, socket being delimited by dashes; 10 , juv. 2nd st., ant. III, anterior view; 11, juv. 3rd st., ant. III, anterior view; 12, juv. 4th st., ant. III, anterior view; 13-15, schematic representations of Figs. 10-12, setae 
the following criteria: the girandole-wise organization of the cuticle architecture, the invaginated antennal III organ, the mucronal morphology, and the absence of the postantennal seta.

Dallai (1972) observed the same cuticle architecture in C. bremondi and C. marginata. As far as the antennal III organ is concerned, the remark of Betsch \& Betsch-Pinot (1984: 74) ought to be retained: "Le caractère libre ou enfoui des sensilles de l'organe antennaire III nous semble trop variable, tant à l'intérieur des genres qu'à l'intérieur d'une même espèce, pour être retenu dans une diagnose générique." Nevertheless, it is true that Caprainea is really a "good genus".

Besides the synapomorphies in common with Gisinurus (size reduction of the tibiotarsal ov. org., presence of (TI1)FSp, ontogenetic delay of (DE)IIp, etc.), Caprainea has the following apomorphic characters: presence of (TI2)FSp and (DE)3pe, acanthoids on inner side of dentes, and regression of pseudonychia.

Three species are described in this genus: $C$. echinata (Stach, 1930), C. marginata (Schött, 1893), and C. bremondi (Delamare \& Bassot, 1957). The two last-mentioned species have been studied.

\section{Caprainea bremondi (Delamare \& Bassot, 1957)}

(Figs. 18-23, Table III)

Material examined. - Spain, prov. Viscaya, between Castillo y Elejabeitia and Gallartu; undergrowth of Pine, Hazel-tree and Chestnut-tree, stream bank, very damp place with Saxifraga hirsuta L., Athyrium filix-femina Roth, Polystichum filix-mas Roth, Oxalis sp., etc.; collected with a net by Nayrolles (PB5b); 10-VII-1987; 5 specimens; 1 \& mounted.

Same place, litter of maritime Pine and Chestnut-tree; fauna extraction with Berlese by Nayrolles (PB5c); 28-V-1990; 26 specimens; 1 \% mounted.
Same place, mosses near the stream; fauna extraction with Berlese by Nayrolles (PB5d); 28-V-1990; 55 specimens; 21 juvs. and 8 adults mounted.

Description. - Number of juv. st. $=4$.

Size ad. male: $0.6-0.75 \mathrm{~mm}$; female: $0.7-$ $1.2 \mathrm{~mm}$.

Color (Fig. 18). Background white or yellow. Flanks of great abd. with two pairs of very dark purple patches, one anterior, one posterior, and between both a light stripe. This stripe has its dorsal part more anterior than its ventral one. Dorsally, a fore narrow dark strip, rather short, and a long hind crenellated band. A small brown spot at basis of trichobothrium A. Small abd., light. Head with violet at the bottom of frons and on the clypeolabral area. A very dark spot on frontal eye. Antennae purple. Legs with violet pigment, furcula with very few pigment. Large (old) females have dark pigment spreading all over body and head. Such specimens absolutely look like $C$. marginata.

Great abd. Trichobothria: A, B, C appear at 2nd st., in very open inverted pattern. Dorsal setae: great macrochaetae straight, pointed, and weakly rough.

Antennae (Figs. 20-21). Antennal ratios: nearly the same for both sexes: ant.I : II : III : IV $=1$ : $2.1: 3.3: 8.3$ and ant. $:$ ceph. diag. $=1.8$. Chaetotaxic variables: for $G: m=132.9 / \mathrm{s}=3.47 / \mathrm{min}$ $=126 / \max =139$; for $I S h^{*}: m=0.97 / s=0.041$ $/ \min =0.87 / \max =1.04$; for $R S h: m=0.76 /$ $s=0.026 / \min =0.72 / \max =0.81$. Note: presence of some microchaetae on ant. II, ant. III with a quite pronounced neochaetosis and differentiation of 5 macrochaetae, and absence of apical bulb on ant. IV. Antennal III organ close to inner side, its two setae being not small.

of $\mathrm{Ge}$ and $\mathrm{Gi}$ drawn as those of antennal III organ (Xe, Xi) and its guard setae (Aai, Api, Ape), other setae are schematized as follows: a full symbol for a seta on reader's side (thus on anterior side), an empty symbol for a seta on opposite of reader's side, a ring for a primary seta, and a triangle for a secondary seta (the symbols of secondary setae belonging to a same generatrix are linked together by a line which is continuous on the anterior side and discontinuous on the other side); 16, juv. 4th st., section A of ant. IV, anterior view; 17, schematic representation of Fig. 16, setae of Ge and Gi drawn: a full symbol for a seta on reader's side (thus on anterior side), an empty symbol for a seta on opposite of reader's side, a ring for a primary G seta except AIIpe schematized by a star, a triangle for a secondary seta, and a square for a $\mathrm{H}$ seta (setae belonging to a same whorl are linked together by a line which is continuous on the anterior side and discontinuous on the other side). 
Table II. Appendicular chaetotaxy of Gisinurus malatestai.

\begin{tabular}{|c|c|c|c|c|c|c|c|c|c|c|c|c|}
\hline \multirow{3}{*}{$\frac{A P}{A D}$} & $\Delta$ & \\
\hline & $\Pi$ & \multicolumn{11}{|c|}{$\frac{-}{-}$} \\
\hline & $\Delta$ & \multicolumn{11}{|c|}{$D:$ io $\quad T: i+1 \quad Q: a+1, i+2$} \\
\hline \multirow[t]{5}{*}{ AT } & $\Pi$ & \multicolumn{11}{|c|}{$=$} \\
\hline & \multirow[t]{4}{*}{$\Delta$} & & & Ge & Gao & $\mathbf{G a}$ & Gai & Gi & Gpi & Gp & Gpe & \multirow{4}{*}{$\begin{array}{l}\text { Other setae: } Q: a \theta+2, a+2 \quad C: a i+2, p \theta+2 \\
\text { Api moves towards basis during development. }\end{array}$} \\
\hline & & & Setae -1 & & $T$ & 0 & $T$ & $\mathbf{Q}$ & $T$ & a & $T$ & \\
\hline & & & Setae 0 & $\mathbf{T}$ & $\mathbf{D}$ & D & & D & D & & D & \\
\hline & & & Setae +1 & & $T$ & $T$ & $T$ & & & a & $\mathbf{T}$ & \\
\hline \multirow[t]{6}{*}{$A Q$} & str & \multicolumn{11}{|c|}{$\begin{array}{l}\text { B completely zoned, with subdivision of } B M \text { in two parts: BM1 and BM2. Section } M \text { euwhorled with } 10 \text { whorls. Right } \\
\text { euwhorlation. } \\
\text { Subsegmentation formula: } 1+12+1-(A)+(M 1,10+B A+B M 1)+(B M 2+B B) \text {. Right subsegmentation. }\end{array}$} \\
\hline & \multirow[t]{3}{*}{$\bar{A}$} & $\Pi$ & \multirow{2}{*}{\multicolumn{10}{|c|}{ AA, Alp, Alpi, Allpi }} \\
\hline & & $\mathrm{H}$ & & & & & & & & & & \\
\hline & & $\bar{\Delta}$ & \multicolumn{10}{|c|}{$\begin{array}{l}\text { Apical bulb: joined to the apex } \\
\text { Allpe is bacilliform }\end{array}$} \\
\hline & \multirow[t]{2}{*}{$\begin{array}{l}\text { M } \\
\mathbf{8} \\
\mathbf{B}\end{array}$} & $\mathbf{H}$ & \multicolumn{10}{|c|}{$\begin{array}{l}\text { Heae does not reach BA. For Heas }: m=9.0 ; \min =9 ; \max =10 \text {. } \\
\text { Hppe reaches BA. For Hppo }: m=10.2 ; \min =9 ; \max =11 . \\
\text { For } h^{*}: m=9.6 ; \min =9.0 ; \max =10.0 \text {. }\end{array}$} \\
\hline & & $\mathbf{G}$ & \multicolumn{10}{|c|}{$\begin{array}{l}\text { Setae of BB: P: BBe, BBpe T: BBae, BBp / BA with one variable seta: BApi }(O C=0.2) / n 80 \%(B M)=8-10 / \\
\text { n80\% }(B)=18-21 / \text { some G setae on } M \text { are sometimes lacking / } n 80 \%(G)=118-122 \text {. } \\
\text { M1ae, M1pi, M2i, M4i, BBae, BBp are cucumiform. }\end{array}$} \\
\hline
\end{tabular}

\begin{tabular}{|c|c|c|c|c|}
\hline \multirow[t]{2}{*}{ SB } & pre & - & + & \multirow{2}{*}{$\frac{+}{P: 1 \text { seta }}$} \\
\hline & $\Delta$ & P: 1 seta & P: 1 seta & \\
\hline \multirow{2}{*}{\begin{tabular}{|l}
$S A$ \\
$C X$ \\
\end{tabular}} & $\Delta$ & - & P: 1 seta & P: 1 seta \\
\hline & $\Delta$ & P:i1 & P:av, i1, ms T:Oi1 & P: ae, i1, ms T: a, Oi1 \\
\hline \multirow[t]{2}{*}{ TR } & $\Pi$ & - & - & - \\
\hline & $\Delta$ & Q: pi & $\begin{array}{l}\mathrm{T}: \mathrm{Oi1}, \mathrm{Oi2} \quad \mathrm{Q}: \mathrm{ac} \\
\text { (C): } \mathrm{a2}(\infty \mathrm{c}=0.8)\end{array}$ & $\begin{array}{l}\mathrm{T}: \text { Oi1, Oi2 Q: ae, a2 } \\
\mathrm{p} \text { is an acanthoid }\end{array}$ \\
\hline \multirow[t]{2}{*}{ FE } & $\Pi$ & - & - & pe1 \\
\hline & $\Delta$ & $\begin{array}{l}\text { delayed primordial seta: } Q: a 03 \\
\text { T: pe3, } O p \quad Q \quad Q: p 2 \\
\begin{array}{ll}\text { (Q)C: } p e 2(o c=0.3) \quad \text { C: } a 2\end{array}\end{array}$ & $\begin{array}{ccc}\text { T: a5 } & \text { Q: ais, pe3, Op } & \text { C: }: a 2 \\
& (C): p e 2(0 c=0.3)\end{array}$ & $T: 25$, ai2 Q: a2, ai4, ai5, pe3, Op \\
\hline \multirow[t]{4}{*}{$\pi$} & $\Pi$ & Ili & Ili, $V_{p}$ & Ili, Vp \\
\hline & $\mathrm{K}$ & - & - & - \\
\hline & FP & + & + & + \\
\hline & $\Delta$ & 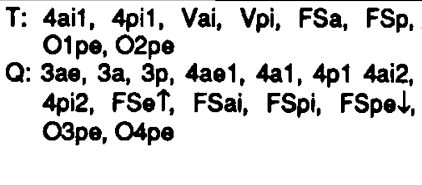 & $\begin{array}{l}\text { T: 4ai1, 4i1, Vai, Vpi, FSa, O1po, } \\
\text { O2pe } \\
\text { Q: 3ae, 3a, 3p, 4ae1, 4a1 4pi1, 4p1, } \\
\text { 4ai2, 4pi2, FSe } \uparrow, \text { FSai, FSpi, } \\
\text { O3pe, O4pe, FSpe } \downarrow\end{array}$ & 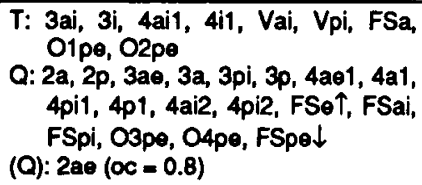 \\
\hline
\end{tabular}

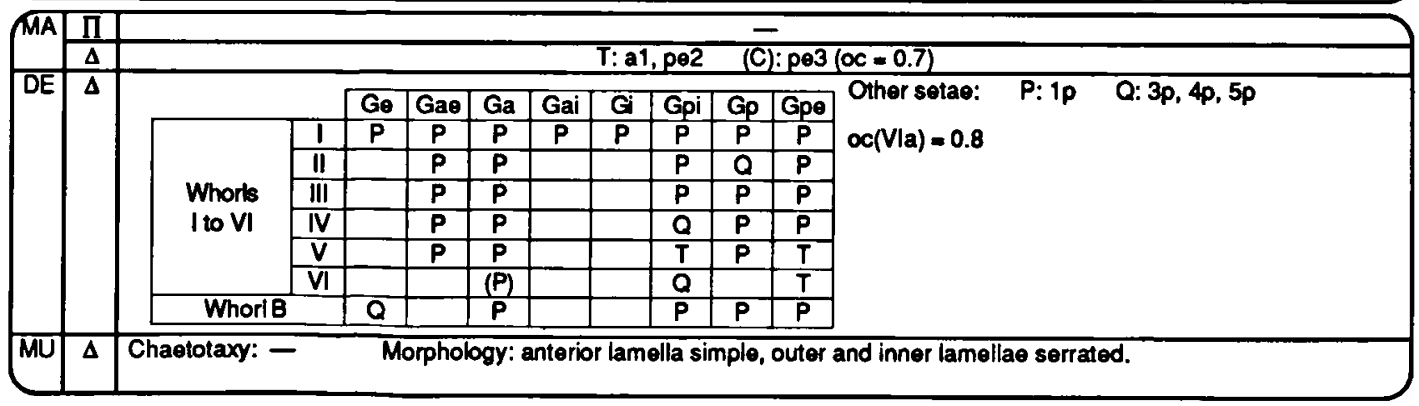




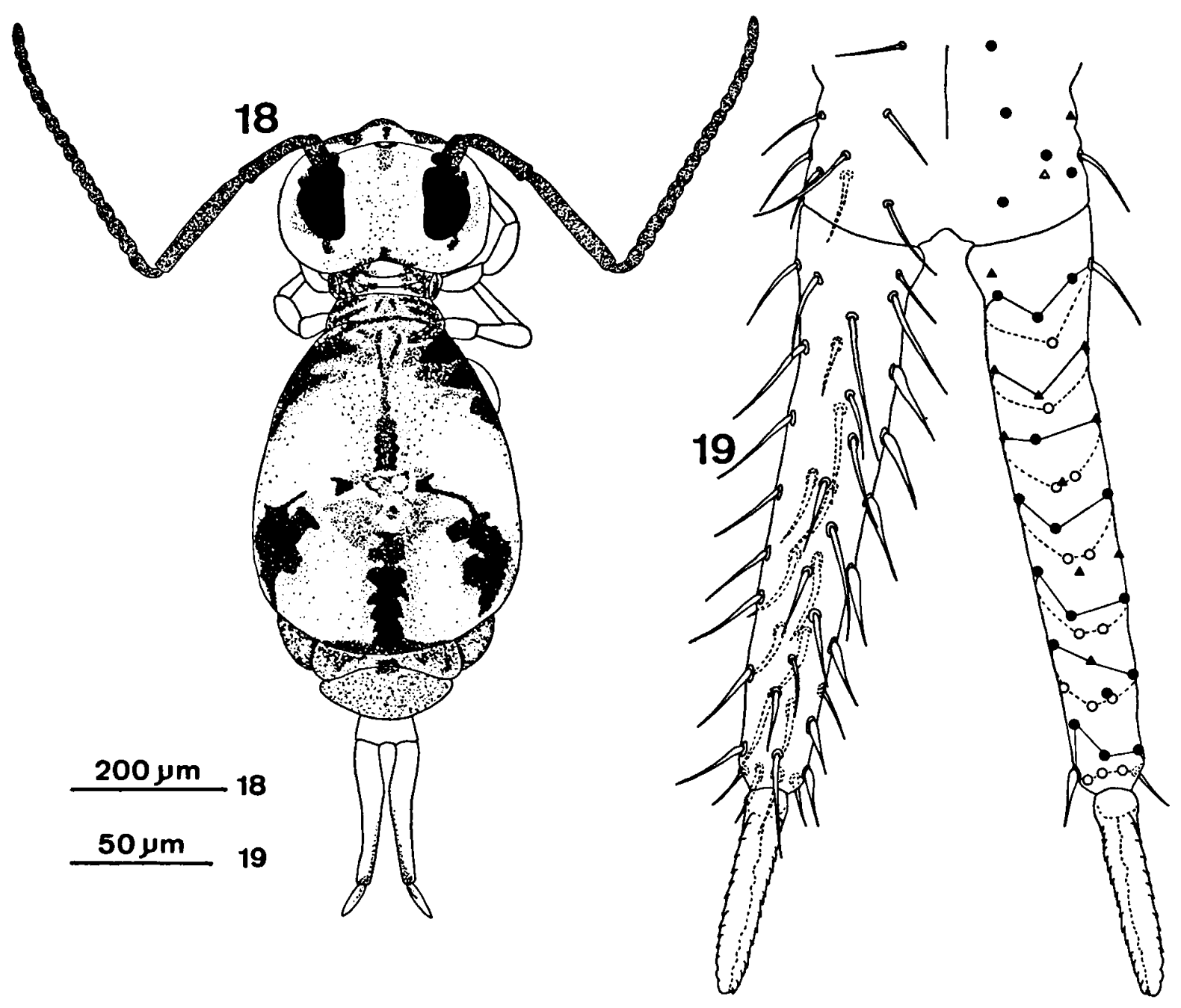

Figs. 18-19. Caprainea bremondi ad.: 18, habitus; 19, furcula, posterior view; on the right, schematic representation as follows: setae of Ge and Gi drawn, a full symbol for a seta on reader's side (thus on posterior side), an empty symbol for a seta on opposite of reader's side, a ring for a primary seta, and a triangle for a secondary seta (setae belonging to a same whorl are linked together by a line which is continuous on the posterior side and discontinuous on the other side).

Head. Eyes: $8+8$; eyepatch with 2 setae. Cephalic setae rather long. Some thick macrochaetae between eyes and on vertex. On inner side of eyepatches $2+2$ acanthoids. Labral formula: 6/5-5-4.

Legs. One seta appears on SA3 at 4th st. Femur: cup present. Tibiotarsi with very slender ov. org.; long setae on outer side. (TI1,2)FSp present. Claws of all legs with a tunica and reduced pseudonychia (Fig. 22). The tunica and pseudonychia grow during development. All legs with a tooth on inner crest of claw. Empodial appendage with a long filament and a tooth at basis of outer lamella.

Ventral tube. Sacs very weakly warty at 2 nd st., clearly warty from 3rd. Chaetotaxy: apical flaps with one pair of primary setae, corpus with a pair from 4th st.

Retinaculum. At 1st st. rami tridentate, bidentate from 2nd. Chaetotaxy: on anterior lobe one pair of setae appears at 3 rd st.

Furcula (Fig. 19). Most noteworthy characters on dentes are: ontogenetic delay of IIp, presence of 3 pe, change into acanthoids of Ii just like setae of 
Table III. Appendicular chaetotaxy of Caprainea bremondi.

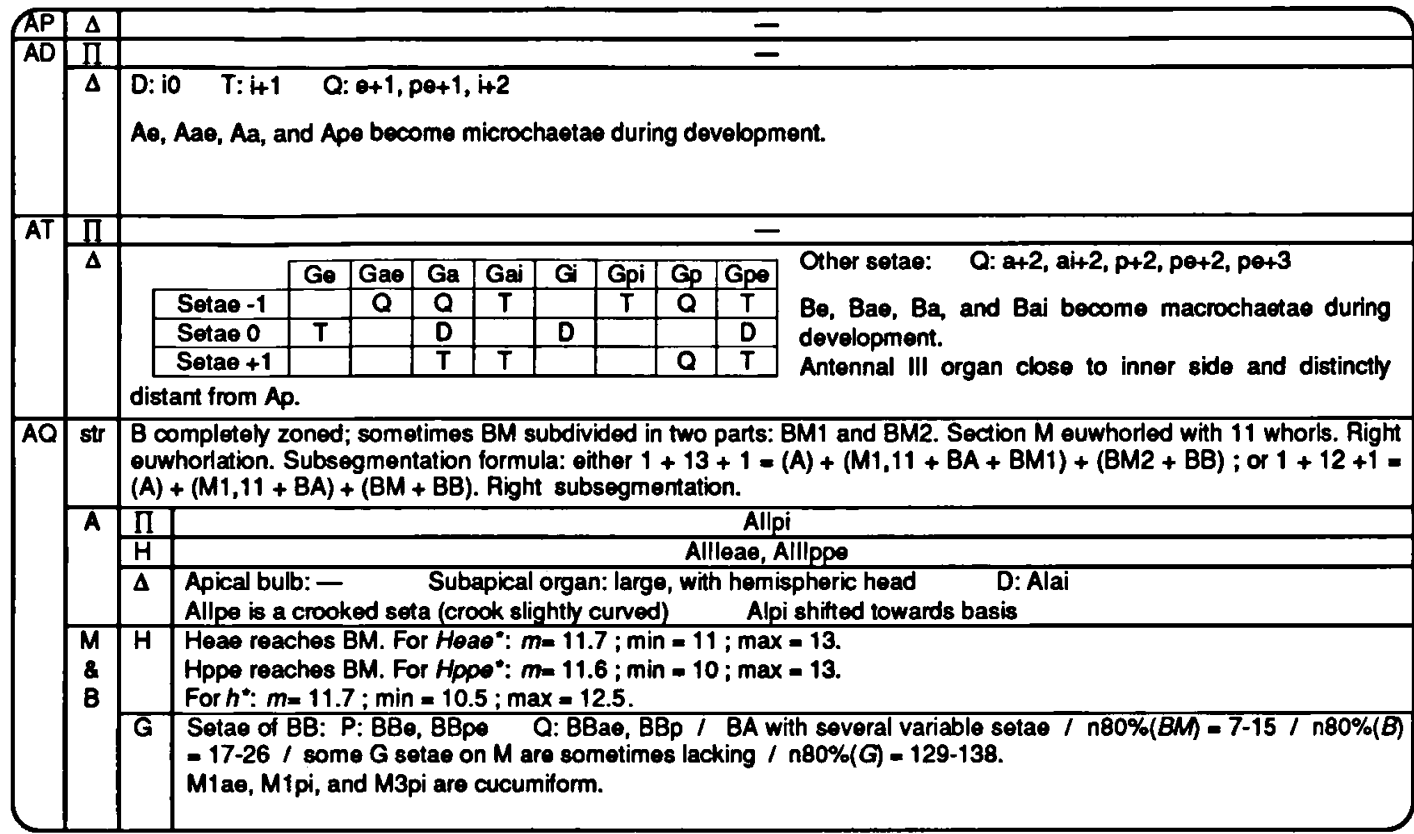

\begin{tabular}{|c|c|c|c|c|}
\hline \multirow[t]{2}{*}{$S B$} & pre & - & + & \multirow{2}{*}{$\frac{t}{P: 1 \text { sota }}$} \\
\hline & $\Delta$ & $P: 1$ seta & $P: 1$ seta & \\
\hline SA & $\bar{\Delta}$ & - & $P: 1$ seta & P:1seta Q: 1seta \\
\hline $\mathrm{CX}$ & $\Delta$ & $\bar{P}:$ i1 & $P: a \theta, i 1, m s \quad Q: O i 1$ & $P: a \theta, i 1, m s \quad T: a$, Oi1 $\quad$ Q: ai2 \\
\hline \multirow[t]{2}{*}{ TR } & $\bar{\Pi}$ & - & $\overline{-}$ & - \\
\hline & $\Delta$ & Q: pi & T: Oi1, Oi2 Q: ae & $\begin{array}{c}\mathrm{T}: \mathrm{a2}, \mathrm{Oi1}, \mathrm{Oi2} \quad \mathrm{Q}: \mathrm{ae} \\
\mathrm{p} \text { is an acanthoid }\end{array}$ \\
\hline \multirow[t]{2}{*}{ FE } & $\Pi$ & $=$ & $=$ & $p=1$ \\
\hline & $\Delta$ & $\begin{array}{cc}\text { delayed primordial seta: } & Q: a \theta 3 \\
T: p \oplus 2 & Q: p 2, p \oplus 3, O_{p}\end{array}$ & Q: a5, ai2, pe2, pe3, Op $\quad$ C: a2, ai5 & $\begin{array}{c}\text { T: a5, ai2 } \\
\text { Q: a2, ai3, ai4, ai5, pө2, pө3, op }\end{array}$ \\
\hline \multirow[t]{4}{*}{$\pi$} & $\bar{\Pi}$ & la & la, Vp & la, $\mathbf{V p}$ \\
\hline & $\mathrm{K}$ & - & - & - \\
\hline & FP & + & + & + \\
\hline & $\Delta$ & $\begin{array}{l}\text { T: 4ai1, 4pi1, Vai, Vpi, FSa } \\
\text { Q: 2ae, 3ae, 3a, 3p, 4ae1, 4a1, 4p1, } \\
\text { 4ai2, 4pi2, FSe } \uparrow, \text { FSai, FSpi, FSp, } \\
\text { FSpe } \downarrow \text {, O1ae, O1pe, O2pe, O3pe, } \\
\text { O4pe }\end{array}$ & $\begin{array}{l}\text { T: 4ai1, 4i1, Vai, Vpi, FSa } \\
\text { Q: 2ae, 3ae, 3a, 3p, 4ae1, 4a1, 4pi1, } \\
\text { 4p1, 4ai2, 4pi2, FSe } \uparrow, \text { FSai, FSpi, } \\
\text { FSp, FSpe } \downarrow \text {, O1ae, O1pe, O2pe, } \\
\text { O3pe, O4pe }\end{array}$ & $\begin{array}{l}\text { T: 3ai, 3i, 4ai1, 4i1, Vai, Vpi, FSa } \\
\text { (T)Q: O2pe (oc = 0.5), O3pe (oc = 0.6) } \\
\text { Q: 2ae, 2a, 2p, 3ae, 3a, 3pi, 3p, 4ae1, } \\
\text { 4a1, 4pi1, 4ai2, 4pi2, FSeT, FSai, } \\
\text { FSpi, FSpe } \downarrow \text {, O1ae, O1pe, O4pe }\end{array}$ \\
\hline
\end{tabular}

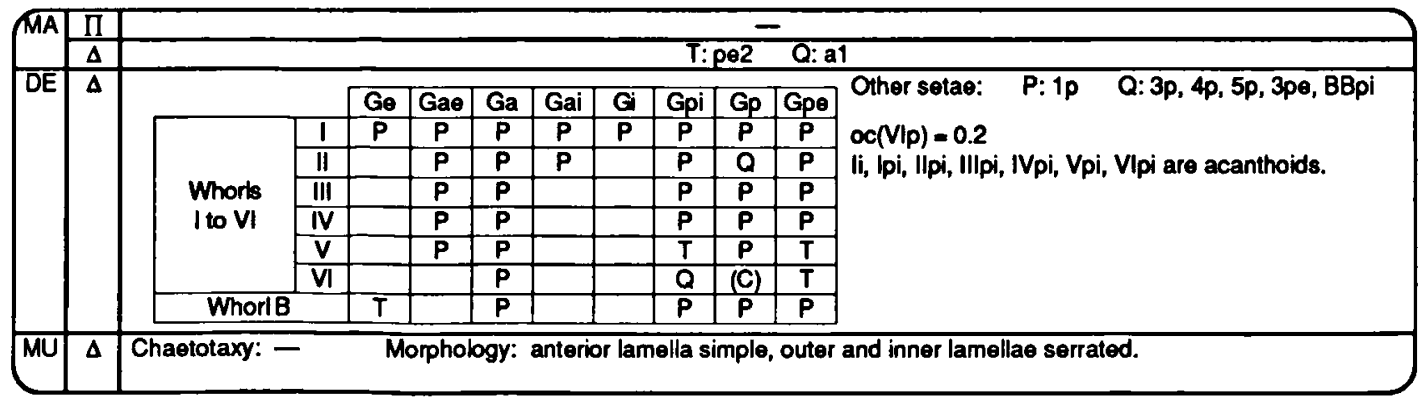




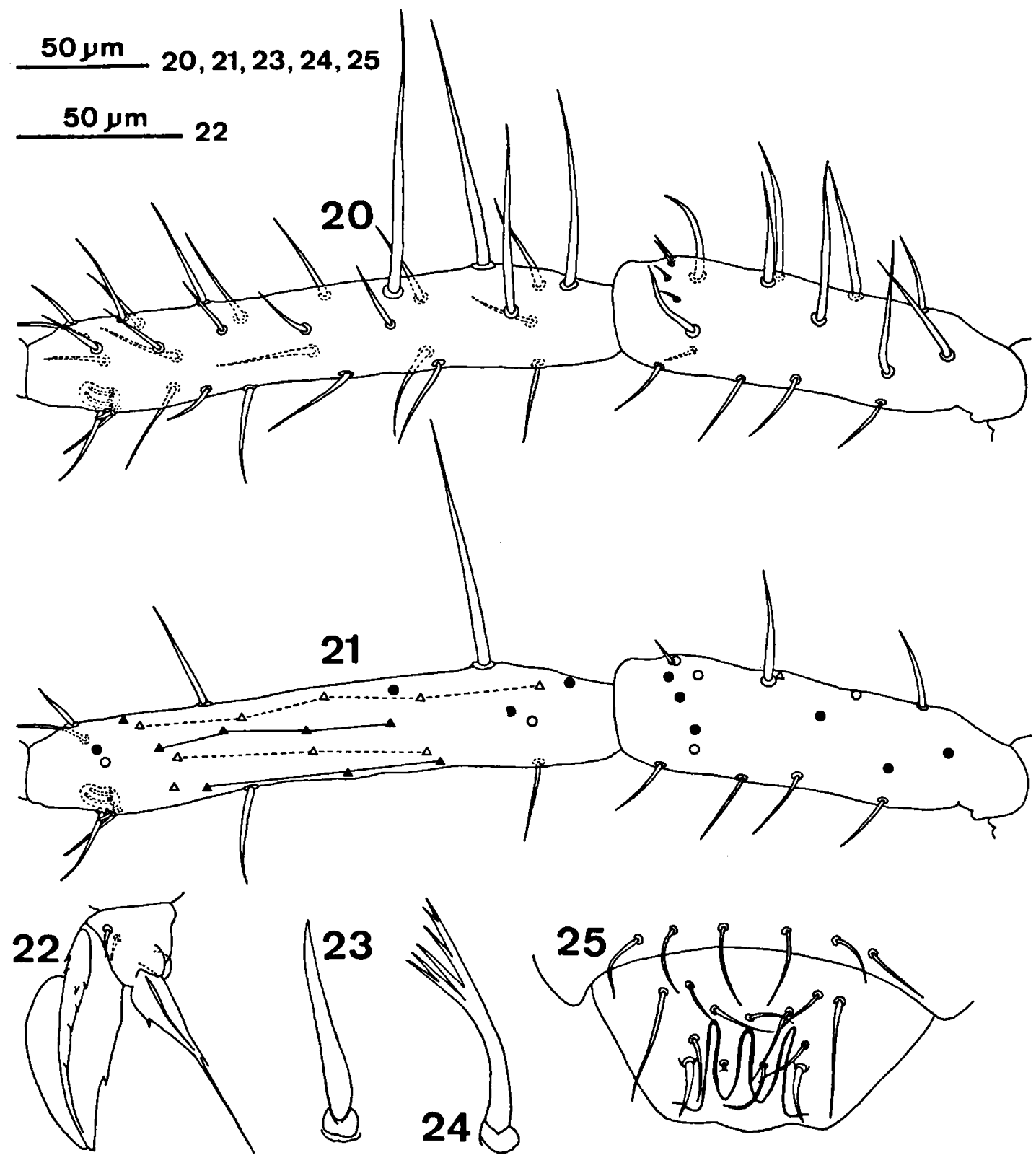

Figs. 20-23. Caprainea bremondi ad.: 20, ant. II and ant. III, anterior view; 21, schematic representation of Fig. 20 (same legend as in Figs. 13-15); 22, mesopretarsus, anterior view; 23, an. app.

Figs. 24-25. Caprainea marginata ad.: 24, an. app.; 25, labrum.

Gpi on whorls I to IV. BBpi present and mucronal seta absent.

Small abd. Made up of abd. V + abd. VI. Trichobothrium: D. Genital papilla of male with about a little less than 20 setae. An. app.: strongly acanthoid, on a papilla (Fig. 23). Ratio an. app.: mucro $=0.9$.
Caprainea marginata (Schött, 1893)

(Figs. 24-25, Table IV)

Material examined. - France, dep. Aveyron, district Bessuéjouls, locality Le Plateau de la Justice, alt. $450 \mathrm{~m}$; grove of Quercus pubescens Willdenow; fauna extraction with Berlese by Nayrolles (AV1b). Several collections from 9-II-1987 until 
Table IV. Appendicular chaetotaxy of Caprainea marginata.

\begin{tabular}{|c|c|c|c|c|c|c|c|c|c|c|c|c|}
\hline \multirow{3}{*}{$A P$} & \multirow{2}{*}{$\bar{\Delta}$} & \multicolumn{11}{|c|}{ - } \\
\hline & & \multicolumn{11}{|c|}{$-2-1-2$} \\
\hline & $\Delta$ & \multicolumn{11}{|c|}{ D: io $\quad T: i+1 \quad Q: \theta+1, p \theta+1, i+2$} \\
\hline \multirow[t]{6}{*}{ AT } & $\Pi$ & \multicolumn{11}{|c|}{ 二 } \\
\hline & \multirow[t]{5}{*}{$\Delta$} & & & $\mathrm{G}_{\theta}$ & Gao & $\mathbf{G a}$ & Gai & Gi & Gpi & $G p$ & $G_{p}$ & \multirow{5}{*}{$\begin{array}{l}\text { Other setae: - } \\
\text { OC(i-1) }=0.3 \\
\text { Be, Bae, Ba, Bai, and Bp become macrochaetae during } \\
\text { development. } \\
\text { n Ap. }\end{array}$} \\
\hline & & & Setae -1 & & & & $\mathbf{Q}$ & (Q)C & $\mathbf{Q}$ & Q & & \\
\hline & & & Setae 0 & $\mathbf{Q}$ & $\mathbf{Q}$ & $\bar{D}$ & & D & & & $\mathbf{D}$ & \\
\hline & & & Setae +1 & & & Q & $\mathbf{Q}$ & & & $\mathbf{Q}$ & & \\
\hline & & \multicolumn{10}{|c|}{ Antennal III organ close to inner side and distinctly distant from Ap. } & \\
\hline \multirow[t]{6}{*}{ AQ } & str & \multicolumn{11}{|c|}{$\begin{array}{l}\text { B completely zoned with subdivision of } B M \text { in two parts: BM1 and BM2. Section } M \text { euwhorled with } 11 \text { whorls. Right } \\
\text { euwhorlation. } \\
\text { Subsegmentation formula: } 1+13+1=(A)+(M 1,11+B A+B M 1)+(B M 2+B B) \text {. Right subsegmentation. }\end{array}$} \\
\hline & \multirow[t]{3}{*}{$\bar{A}$} & $\Pi$ & \multicolumn{10}{|c|}{ Allpi } \\
\hline & & $\mathrm{H}$ & \multicolumn{10}{|c|}{ Alleae, Allppe } \\
\hline & & $\Delta$ & \multicolumn{10}{|c|}{$\begin{array}{l}\text { Apical bulb:- Subapical organ: modium-sized, clavate } \\
\text { Allpe is a crooked seta }\end{array}$} \\
\hline & \multirow[t]{2}{*}{$\begin{array}{l}M \\
\& \\
B\end{array}$} & $\mathrm{H}$ & \multicolumn{10}{|c|}{ 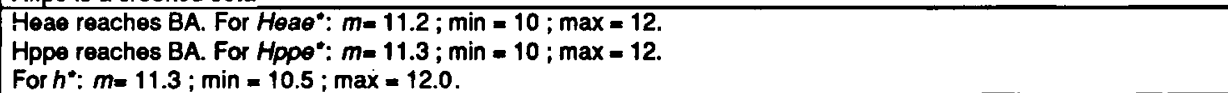 } \\
\hline & & $\mathbf{G}$ & \multicolumn{10}{|c|}{$\begin{array}{l}\text { Setae of BB: P: BBe, BBpe Q: BBae, BBp / BA with one variable seta: BApi }(O C=0.4) / n 80 \%(B M)=8-13 \text { / } \\
\text { n80\% }(B)=19-24 / \text { some } G \text { setae on } M \text { are sometimes lacking / } n 80 \%(G)=130-136 \text {. } \\
\text { M1ae and M1 pi are cucumiform. }\end{array}$} \\
\hline
\end{tabular}

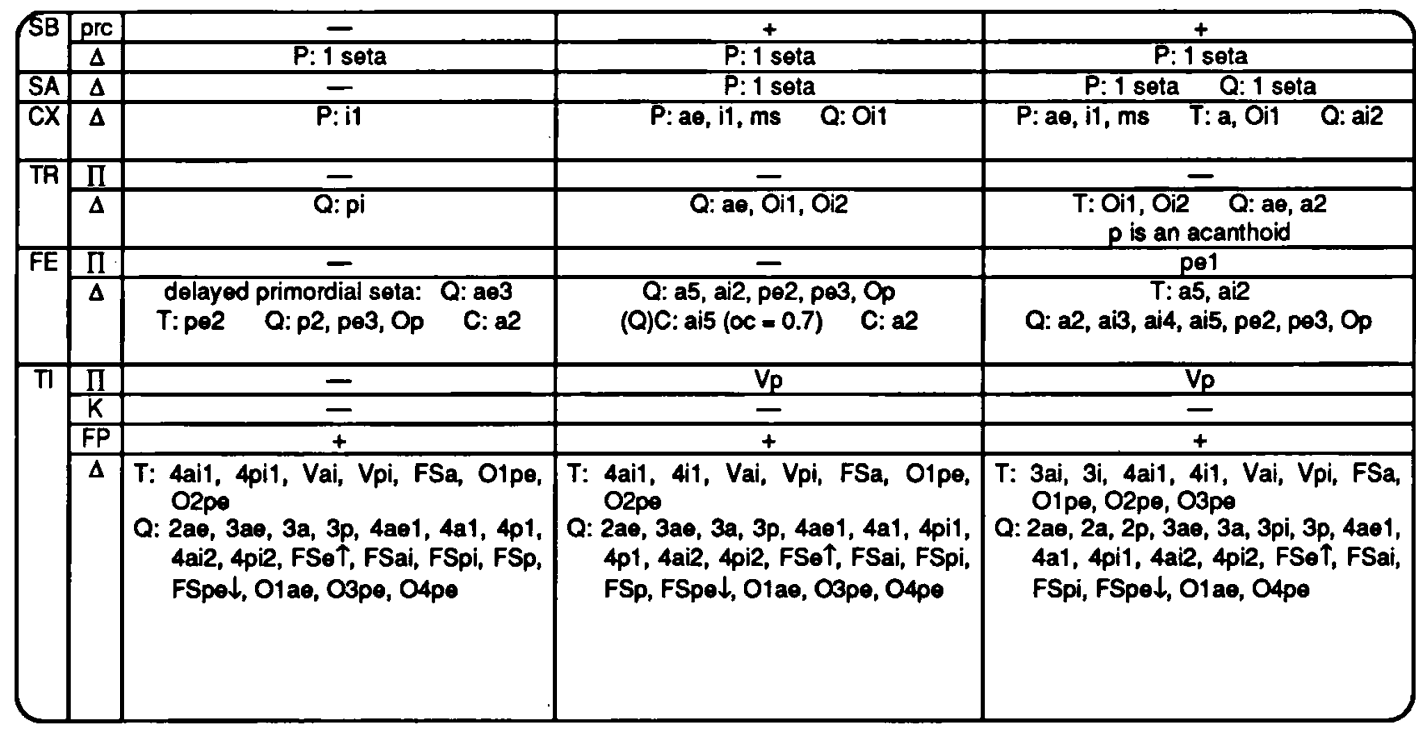

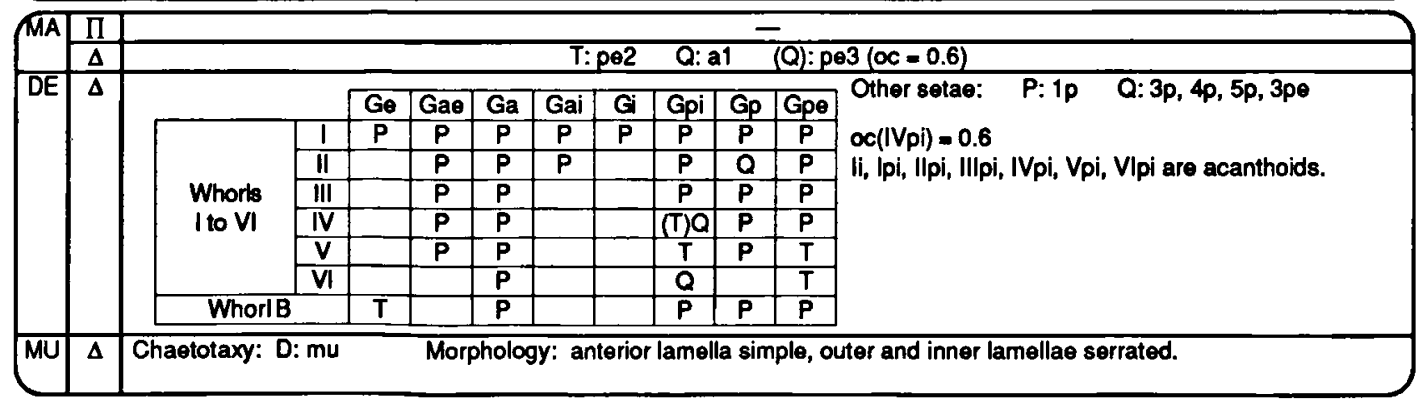


27-I-1988, and 27-V-1990. About a hundred specimens; 49 juvs. and 13 adults mounted.

Description. - Number of juv. st. $=4$.

Size ad. male: $0.6-0.8 \mathrm{~mm}$; female: $0.8-1.2$ $\mathrm{mm}$.

Color. Background dark purple with more or less rusty shades. Whole body with pigment, legs and furcula included. Color of body uniform. Head slightly lighter than body. Eyepatches black and quite large. Body globular.

Great abd. Trichobothria: A, B, C appear at 2nd st., in very open inverted pattern. Dorsal setae: great macrochaetae straight, pointed, and weakly rough.

Antennae. Antennal ratios: in both sexes, ant. I : II : III : IV = 1 : $2.1: 3.2: 8.6$; ant.: ceph. diag. $=2.1$ in male and 1.9 in female. Chaetotaxic variables: for $G: m=132.6 / s=2.25 / \min =127 /$ $\max =136$; for $I S h^{*}: m=0.94 / s=0.032 / \mathrm{min}$ $=0.87 / \max =1.00$; for $R S h: m=0.74 / s=$ $0.025 / \min =0.69 / \max =0.81$. Note: ant. III with 5 macrochaetae, antennal III organ being close to inner side and its two setae not small, and absence of apical bulb on ant. IV.

Head. Eyes: $8+8$; eyepatch with 2 setae. Cephalic setae long. Some thick macrochaetae between eyes and on vertex. On inner side of eyepatches $2+2$ acanthoids. Labral formula noteworthy: 6/4-5-4 (Fig. 25).

Legs. One seta appears on SA3 at 4th st. Femur: cup present. Tibiotarsi with very slender ov. org.; long setae on outer side (TI1,2)FSp present. Claws of all legs with a tunica and reduced pseudonychia. The tunica and pseudonychia increase during development. All legs with a tooth on inner crest of claw. Empodial appendage with a long filament and a tooth at basis of outer lamella.

Ventral tube. Sacs weakly warty at 3rd st., wholly warty from 4th. Chaetotaxy: apical flaps with one pair of primary setae, corpus with a pair from 4th st.

Retinaculum. At 1st st. rami tridentate, bidentate from 2nd. Chaetotaxy: on anterior lobe, one pair of setae appears at 3rd st.

Furcula. Same characters as in C. marginata except BBpi absent and mucronal seta present.
Small abd. Made up of abd. V + abd. VI. Trichobothrium: D. Genital papilla of male medium-sized. An. app. branchy, on a papilla (Fig. 24). Ratio an. app.: mucro $=0.8$.

Discussion. - The most interesting seta is (TI.)Ia, because it allows the distinction between the two Caprainea species into every instar of their development. We give two other distinctive characters: in C. bremondi several primary setae on ant. II are microchaetae and the an. app. is thick, whereas in C. marginata setae on ant. II are mesochaetae and the an. app. is branchy. This last criterion has already been given by Da Gama (1961).

\section{Acknowledgements}

I thank Drs. A. Bedos and L. Deharveng for their loan of specimens. I thank also Dr. J.-M. Betsch for his suggestions on the manuscript.

\section{References}

Betsch, J.M., 1980. Eléments pour une monographie des Collemboles Symphypléones (Hexapodes, Aptérygotes). Mém. Mus. natn. Hist. nat., Paris, (A, Zool.) 116: 1-227.

Betsch, J.M. \& M.C. Betsch-Pinot, 1984. Contribution à l'étude des Sminthurus (Collembola, Symphypleona). Annls. Soc. r. zool. Belg., 114(1): 71-81.

Betsch, J.M. \& A. Waller, 1989. L'armement en trichobothries des Collemboles Symphypléones. Recherche de schémas chétotaxiques. In: R. Dallai (ed.), Third International Seminar on Apterygota: 15-31 (Università di Siena, Italy).

Bretfeld, G., 1990. Chaetotaxy of four species of the genera Heterosminthurus, Bourletiella, Deuterosminthurus and Prorastriopes (Insecta, Collembola, Symphypleona). Zool. Jb. Syst., 117: 441-489.

Dallai, R., 1970a. Investigations on Collembola, 10. Examination of the cuticle in some species of the tribe Sminthurini Börner, 1913, by means of the scanning electron microscope. Monitore zool. ital., (N.S.) 4: 41-53.

Dallai, R., 1970b. Ricerche sui Collemboli, XIV. Le Alpi Apuane. Lav. Soc. ital. Biogeogr., (N.S.) 1: 433-482.

Dallai, R., 1972. La cuticola degli Sminthurini al microscopio elettronico a scansione. Atti IX Congr. naz. ital. Ent., Siena, 21-25 Giugno 1972: 217-226, pls. 1-10 (Bertelli \& Piccardi, Firenze).

Gama, M.M. da, 1961. Nouvelle contribution pour l'étude des Collemboles du Portugal continental. Mems. Estud. Mus. zool. Univ. Coimbra, 269: 1-43. 
Gisin, H., 1960. Collembolenfauna Europas: 1-312 (Mus. Hist. nat., Genève).

Grandjean, F., 1939. La répartition asymétrique des organes aléatoires. C. r. hebd. Séanc. Acad. Sci., Paris, 208: 861-864.

Grandjean, F., 1949. Au sujet des variations individuelles et des polygones de fréquence. C. r. hebd. Séanc. Acad. Sci., Paris, 229: 801-804.

Grandjean, F., 1952. Sur les variations individuelles. Vertitions (écarts) et anomalies. C. r. hebd. Séanc. Acad. Sci., Paris, 235: 640-643.

Nayrolles, P., 1988. Chétotaxie tibiotarsale des Collemboles Symphypléones. Trav. Lab. Ecobiol. Arthr. édaph. Toulouse, 5 (4): 1-19, pls. 1-9.

Nayrolles, P., 1989. Données nouvelles sur l'évolution ontogénétique des Collemboles Symphypléones. Nouv. Revue Ent., (N.S.) 6 (3): 231-244.

Nayrolles, P., 1990a. Chétotaxie de la base de la patte des Col- lemboles Symphypléones. Trav. Lab. Ecobiol. Arthr. édaph. Toulouse, 6 (2): 1-26.

Nayrolles, P., 1990b. Chétotaxie furcale des Collemboles Symphypléones. Trav. Lab. Ecobiol. Arthr. édaph. Toulouse, 6 (2): 27-50.

Nayrolles, P., 1991. La chétotaxie antennaire des Collemboles Symphypléones. Trav. Lab. Ecobiol. Arthr. édaph. Toulouse, 6 (3): 1-94.

Richards, W.R., 1968. Generic classification, evolution and biogeography of the Sminthuridae of the world (Collembola). Mem. ent. Soc. Canada, 53: 1-54.

Stach, J., 1956. The apterygotan fauna of Poland in relation to the world-fauna of this group of insects. Family: Sminthuridae: 1-287 (Polska Akad. Nauk Inst. Zool., Krakowie).

Received: 22 September 1992

Revised: 21 December 1992 